\title{
Historic Habitat Opportunities and Food-Web Linkages of Juvenile Salmon in the Columbia River Estuary
}

\author{
Daniel L. Bottom ${ }^{1}$, Charles A. Simenstad ${ }^{2}$, Lance Campbell ${ }^{3}$, Jennifer Burke ${ }^{2}$, \\ Edmundo Casillas ${ }^{1}$, Bethany Craig ${ }^{2}$, Chris Eaton ${ }^{2}$, Susan Hinton ${ }^{1}$, Regan McNatt $^{1}, \mathrm{G}$. \\ Curtis Roegner ${ }^{1}$, Steve Schroder ${ }^{3}$, Lia Stamatiou ${ }^{2}$, \\ and Jeannette E. Zamon ${ }^{1}$
}

Annual Report of Research by

Fish Ecology Division

NOAA Fisheries

Northwest Fisheries Science Center

2725 Montlake Blvd. E.

Seattle, Washington 98112

for

Environment, Fish, and Wildlife Division

Bonneville Power Administration

U.S. Department of Energy

P.O. Box 3621

Portland, Oregon 97208-3621

March 2009

${ }^{1}$ NOAA Fisheries, Northwest Fisheries Science Center, Seattle, WA

${ }^{2}$ School of Aquatic and Fishery Sciences, University of Washington

${ }^{3}$ Washington Department of Fish and Wildlife 


\section{Introduction}

In 2002 with support from the U.S. Army Corps of Engineers (USACE), an interagency research team began investigating salmon life histories and habitat use in the lower Columbia River estuary to fill significant data gaps about the estuary’s potential role in salmon decline and recovery (Bottom et al. 2005; Roegner et al. 2009). The Bonneville Power Administration (BPA) provided additional funding in 2004 to reconstruct historical changes in estuarine habitat opportunities and food web linkages of Columbia River salmon (Onchorhynchus spp.). Together these studies constitute the estuary's first comprehensive investigation of shallow-water habitats, including selected emergent, forested, and scrub-shrub wetlands. Among other findings, this research documented the importance of wetlands as nursery areas for juvenile salmon (Lott 2004; Bottom et al. 2008; Roegner et al. 2009); quantified historical changes in the amounts and distributions of diverse habitat types in the lower estuary (Bottom et al. 2008); documented estuarine residence times, ranging from weeks to months for many juvenile Chinook salmon (O. tshawytscha) (Bottom et al 2008; Roegner et al. 2009); and provided new evidence that contemporary salmonid food webs are supported disproportionately by wetland-derived prey resources (Anderson 2006).

The results of these lower-estuary investigations also raised many new questions about habitat functions, historical habitat distributions, and salmon life histories in other areas of the Columbia River estuary that have not been adequately investigated. For example, quantitative estimates of historical habitat changes are available only for the lower $75 \mathrm{~km}$ of the estuary (Thomas 1983; Bottom et al. 2008), although tidal influence extends $217 \mathrm{~km}$ upriver to Bonneville Dam. Because the otolith techniques used to reconstruct salmon life histories rely on detection of a chemical signature (strontium) for salt water, the estuarine residency information we have collected to date applies only to the lower 30 or $35 \mathrm{~km}$ of the estuary, where fish first encounter ocean water. We lack information about salmon habitat use, life histories, and growth within the long tidalfresh reaches of the main-stem river and many tidally-influenced estuary tributaries. Finally, our surveys to date characterize wetland habitats within island complexes distributed in the main channel of the lower estuary. Yet some of the most significant wetland losses have occurred along the estuary's periphery, including shoreline areas and tributary junctions (Bottom et al. 2008). These habitats may or may not function similarly as the island complexes that we have surveyed to date.

In 2007 we initiated a second phase of the BPA estuary study (Phase II) to address specific uncertainties about salmon in tidal-fresh and tributary habitats of the Columbia River estuary. This report summarizes 2007 and 2008 Phase II results and addresses three principal research questions:

(1) What was the historic distribution of estuarine and floodplain habitats from Astoria to Bonneville Dam?

(2) Do individual patterns of estuarine residency and growth of juvenile Chinook salmon vary among wetland habitat types along the estuarine tidal gradient? 
(3) Are salmon rearing opportunities and life histories in the restoring wetland landscape of lower Grays River similar to those documented for island complexes of the main-stem estuary?

Phase II extended our analysis of historical habitat distribution in the estuary above Rkm 75 to near Bonneville Dam. For this analysis we digitized the original nineteenth-century topographic (T-sheets) and hydrographic (H-sheets) survey maps for the entire estuary. Although all T-sheets (Rkm 0 to Rkm 206) were converted to GIS in 2005 with support for the USACE estuary project, final reconstruction of historical habitats throughout the estuary requires completion of the remaining H-sheet GIS maps above Rkm 75 and their integration with the T-sheets. This report summarizes progress to date on compiling the upper estuary H-sheets above Rkm 75.

For the USACE estuary project, we analyzed otoliths from Chinook salmon collected near the estuary mouth in 2003-05 to estimate variability in estuary residence times among juvenile out migrants. In Phase II we expanded these analyses to compare growth and residency among individuals collected in tidal-fresh water wetlands of the lower main-stem estuary. Although no known otolith structural or chemical indicators currently exist to define entry into tidal fresh environments, our previous analyses indicate that otolith barium concentrations frequently increase before individuals encounter salt water. Here we evaluate whether otolith barium levels may provide a valid indicator of tidal fresh water entry by Columbia River Chinook salmon. We also examine otolith growth increments to quantify and compare recent (i.e., the previous $30 \mathrm{~d}$ ) growth rates among individuals sampled in different wetland habitats along the estuarine tidal gradient.

The Phase II study initiated new surveys in lower Grays River to compare juvenile salmon habitat use and performance in a lower Columbia River tributary estuary with results from the main-stem estuary. This component of our research included three activities that are summarized in this report. First, we designed an experiment to test directly our interpretation that salmon habitat selection in the Columbia River estuary is size dependent (Bottom et al. 2005, 2008). For this test, we differentially marked and released three size classes of hatchery chum salmon (O. keta) fry in Grays River and monitored their distribution and residency in the Grays River estuary. Second, we monitored downstream migration and habitat-use patterns of juvenile coho salmon ( $O$. kisutch) to determine whether tributary estuaries such as Grays River function as coho salmon nursery areas, particularly for juveniles with subyearling life histories. Although subyearling migrants reside for extended periods in many Pacific Coast estuaries (e.g., see Koski 2009), we rarely have encountered coho salmon in near-shore beach seine and wetland sites in the main-stem Columbia River estuary. Third, we surveyed the composition and abundance of benthic invertebrates and fall-out insects and the diets of juvenile Chinook and coho salmon in selected Grays River tidal marshes to compare with similar results from main-stem wetlands (Lott 2004; Bottom et al. 2008; Roegner et al. 2009). This report describes preliminary results from our first full year (2008) of Grays River field studies and their implications for subsequent Phase II research. 


\section{Methods}

\section{Historical Habitat Distribution}

We digitized historical topographic (T-sheet) and hydrographic (H-sheet) surveys in GIS to map the riverine, intertidal and floodplain landscape for the Columbia River estuary. A bathymetric model of the river based on the H-sheet survey maps is complete and extends from the marine waters beyond the Columbia River mouth to Rkm 218, in the vicinity of Rooster Rock State Park (Figure 1).

When the classification of the T-sheets is completed, the H-sheets bathymetric dataset will be merged with the T-sheets land cover class datasets to characterize the spatial distribution and change in area of juvenile salmon habitats, features, and the connectivity of the estuarine surgeplain and other landscape features with the River. We will use a variety of GIS and analytical methods including FRAGSTATS and ESRI ArcTools to characterize the historical landscape (McGarigal et al 2002, ESRI 2009).

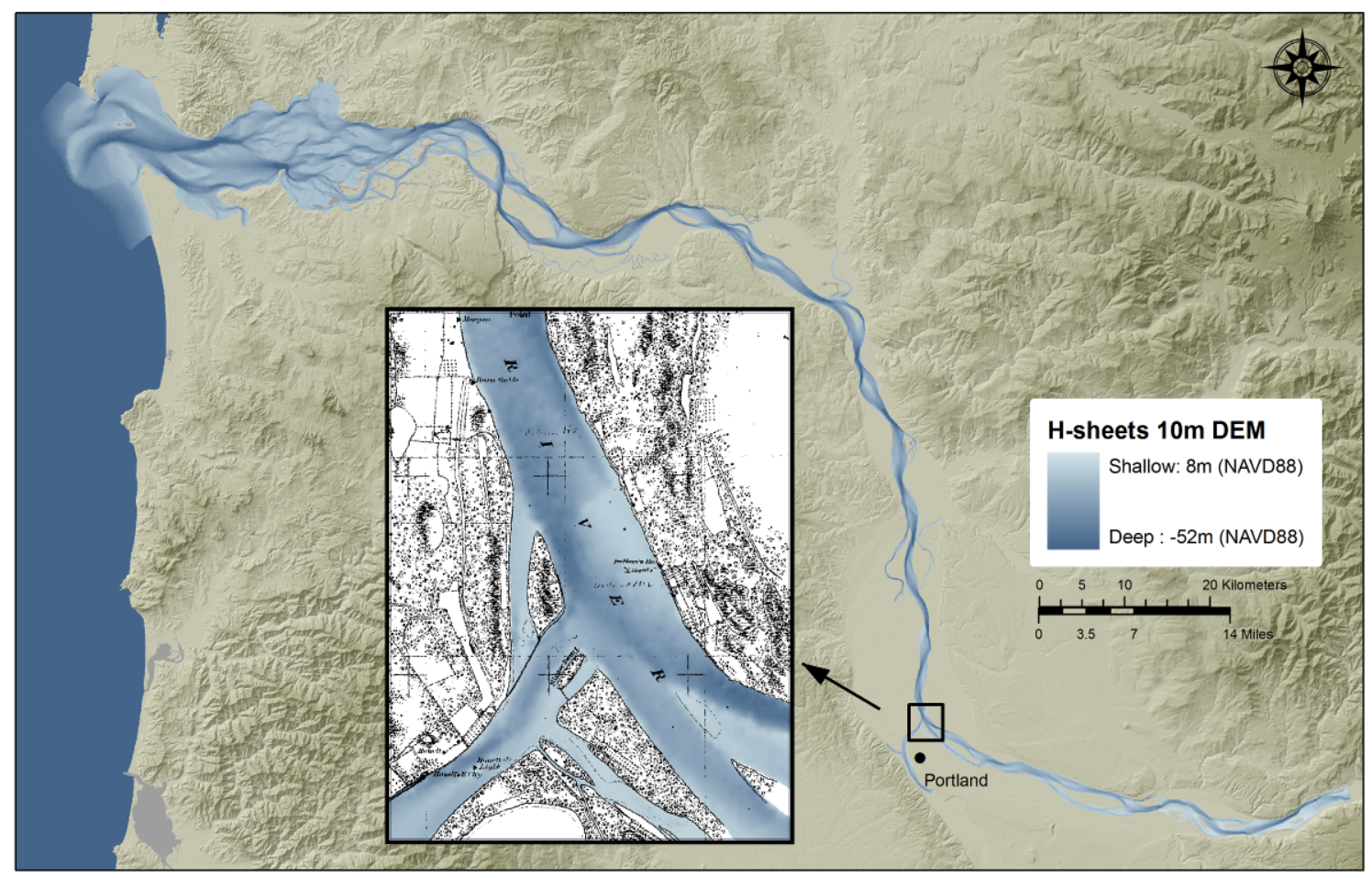

Figure 1. Historical Columbia River estuarine bathymetry derived from the H-sheets and presented as a digital elevation model. The inset map depicts the T-sheet survey map with the H-sheets' bathymetric model at the confluence of the Willamette and Columbia Rivers.

\section{Otolith Analyses}

For life history interpretations, we chemically analyzed 161 juvenile Chinook salmon otoliths collected at four tidal-fresh survey sites distributed between Rkm 35 and 101: Russian Island (2003-06), Welch Is (2004-05), Wallace (2006), and Lord islands 
(2006) (Figure 2). We back-calculated size and atomic ratio values pre- and post- Ba marker (described below) for 98 of the samples, and estimated mean growth rates for 32 of these samples for which daily growth increments (DGI) were satisfactory for analysis.

All juvenile Chinook salmon used for otolith analyses were collected with a fyke trap net deployed within selected wetland channels in the interior of each of the four islands or with a beach seine pulled along the outer (north) shores of Wallace and Lord islands. We also compare these wetland results with otolith barium patterns for fish sampled with a beach seine at Point Adams Beach near the estuary mouth (Figure 2). Details of our fish collection gear and methods are provided in Roegner et al. 2009.

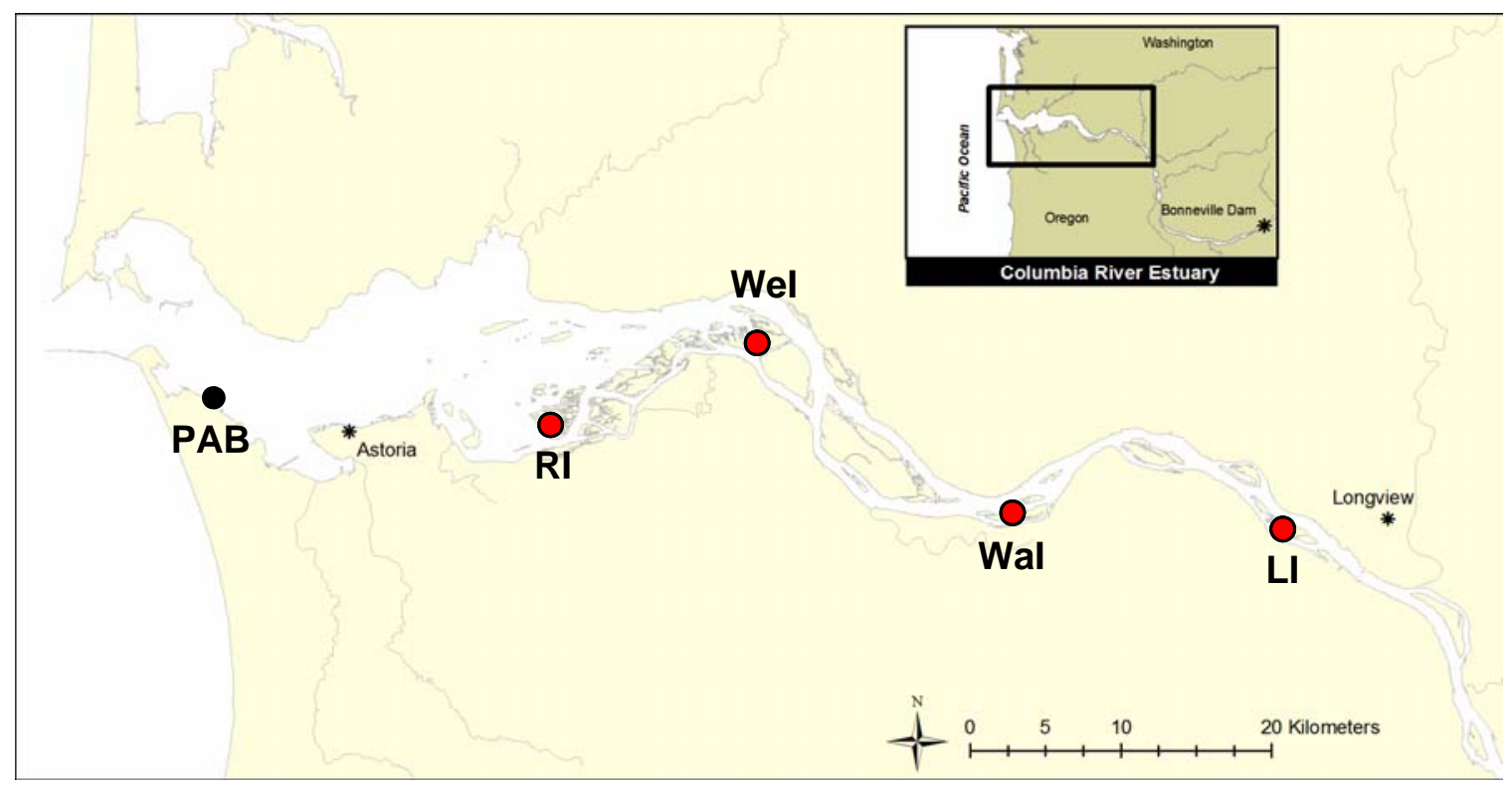

Figure 2. Location of tidal fresh wetland sites where Chinook salmon otoliths were collected for barium analyses: Russian Island (RI), Welch Island (WeI), Wallace Island (WaI), and Lord Island (LI). Results for fish collected at a beach seining site near the river mouth (Point Adams Beach, PAB) are also presented as a comparison of barium otolith patterns.

For each juvenile Chinook sample, we prepared sagiital otoliths for chemical and daily growth increment analysis by thin sectioning in the sagiital plane (methodology modified from Volk et al. 2000 and Zimmerman and Reeves 2002). All chemical analyses were completed at the Keck Collaboratory for Mass Spectrometry at Oregon State University. The analysis system consisted of New Wave DUV $193 \mathrm{~nm}$ ArF laser coupled with a Thermal Elemental PQ Excell quadropole inductively coupled plasma mass spectrometer (LA-ICPMS). On each otolith we traced a laser transect for ablation from the posterior visible primoridium to beyond the otolith edge in the dorsal/posterior quadrant (Figure 3). To quantify Sr86/Ca43 and Ba138/Ca43 atomic ratios after each otolith was analyzed, we ran a transect along a polished NIST (610) glass standard with known concentrations of Strontium (Sr86), Barium (Ba138), and Calcium (Ca43). Raw counts of $\mathrm{Sr}$, Ba and Ca were plotted, and points of interest (POI) were recorded for 
transect start and end points and the point of increasing $\mathrm{Sr}$ and $\mathrm{Ba}$, identified visually as the transition between low and high levels of $\mathrm{Ba}$ and $\mathrm{Sr}$ concentration. We related chemical POI to a specific location on each otolith according to the following equation (Brenkman et al. 2007):

Distance from edge $(\mu \mathrm{m})=(($ Time Margin $(\mathrm{msec})-$ Time $(\mathrm{POI})) / 1000 * 5 \mu \mathrm{m})$.

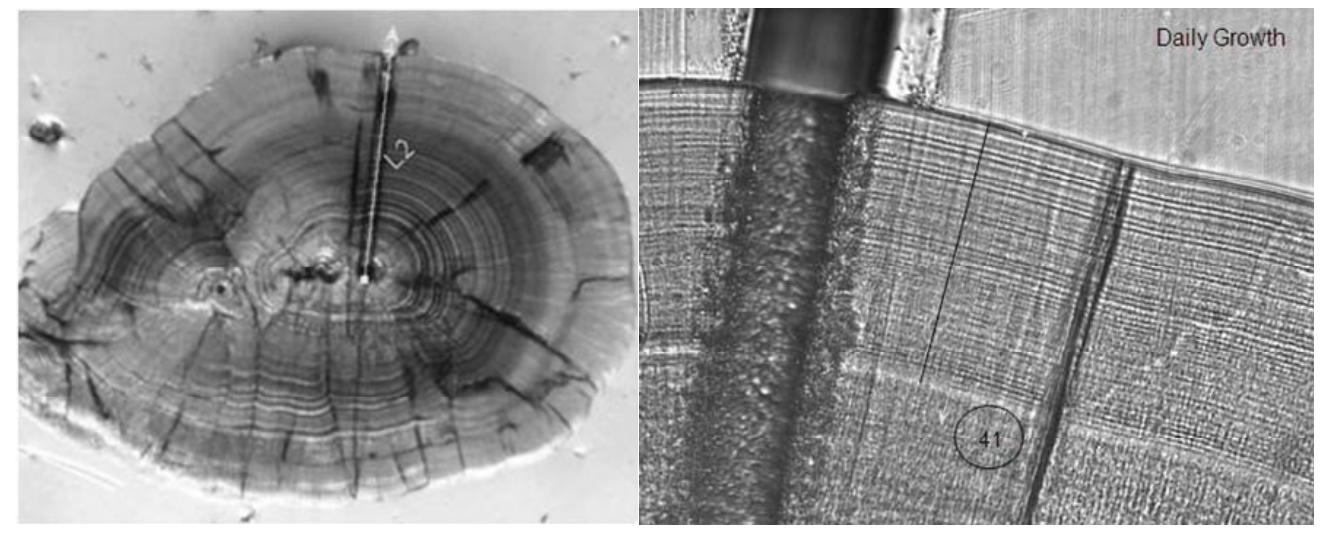

Figure 3. Juvenile Chinook salmon otolith (left) showing primordia and laser scar (L2). Daily growth increments and laser scar magnified 400X (right).

We used Campana’s (1990) proportional Biological Intercept (BI) method to back calculate the fish size at a given otolith size based on the formula:

$$
L a=L c+(O a-O c)(L c-L o)(O c-O o)^{\wedge}-1,
$$

where Lc and Oc are the size of the fish and otolith at the time of capture; Lo and Oo are the biological intercept for fish length and otolith size, respectively; and La and Oa are the size of the fish and the otolith at a particular POI, such as the point of $\mathrm{Ba}$ or $\mathrm{Sr}$ increase.

To estimate mean daily growth rates for juvenile Chinook salmon, we used a Coolsnap-Pro digital camera coupled with a Nikon light microscope and Image Pro 6.3 imaging software to measure daily growth increments at $400 \mathrm{X}$ magnification. Measurements were taken from the otolith edge toward the primordium near the laser scar (dorsal/ventral quadrant). Average mean increment widths (MIW) were calculated over the total otolith distance usable for DGI analysis and the previous 7, 15, 30, and 60 increments (days).

\section{Grays River Studies}

\section{Life history experiment}

To evaluate whether salmon habitat use is size dependent, we reared at Grays River Hatchery three experimental groups of chum salmon fry spawned on different dates 
to produce three distinct size classes. We spray marked all fry 24h before release with one of three colors of Fluo Mark ${ }^{\mathrm{TM}}$ fluorescent grit pigment assigned to each of the size groups. We retained a subsample of 175 individuals from each size group to estimate mark retention for each of the spray colors. A total of 147,367 chum salmon fry was released on 29 March 2008, including 49,221 from egg take $\# 1$ (orange, $\bar{x}=51.8 \mathrm{~mm}$, sd 4.1), 78,547 from take \#2 (yellow/green, $\bar{x}=49.3 \mathrm{~mm}$, sd 3.9), and 19,600 from take \#3 (red, $\bar{x}=43.0$, sd 2.4). All groups were released after sunset at a site approximately $5 \mathrm{~km}$ below Grays River Hatchery.

Several beach seining crews conducted daylight surveys beginning the day before release (29 March) and continuing daily after release from 30 March through 1 April. We collected juvenile salmon at five beach seining sites in Grays River estuary (between Rkm 0-7.8), four additional beach seining sites in the NW corner of upper Grays Bay, and three trap net sites in restored or natural wetland channels (Figure 4). During each survey we measured a subsample of up to 100 chum salmon collected at each site. During the last few days of the study, we also evaluated potential holding areas for marked fry by extending the sampling area beyond Rosberg boat launch to Rkm 12.5. All fish collected during the recapture surveys were examined in a darkened box under ultraviolet light to identify spray-marked individuals. On 2 April we also examined under ultraviolet light all individuals from subsamples of each mark group held at Grays River Hatchery to determine the total proportion of each group that retained identifiable spray marks. 

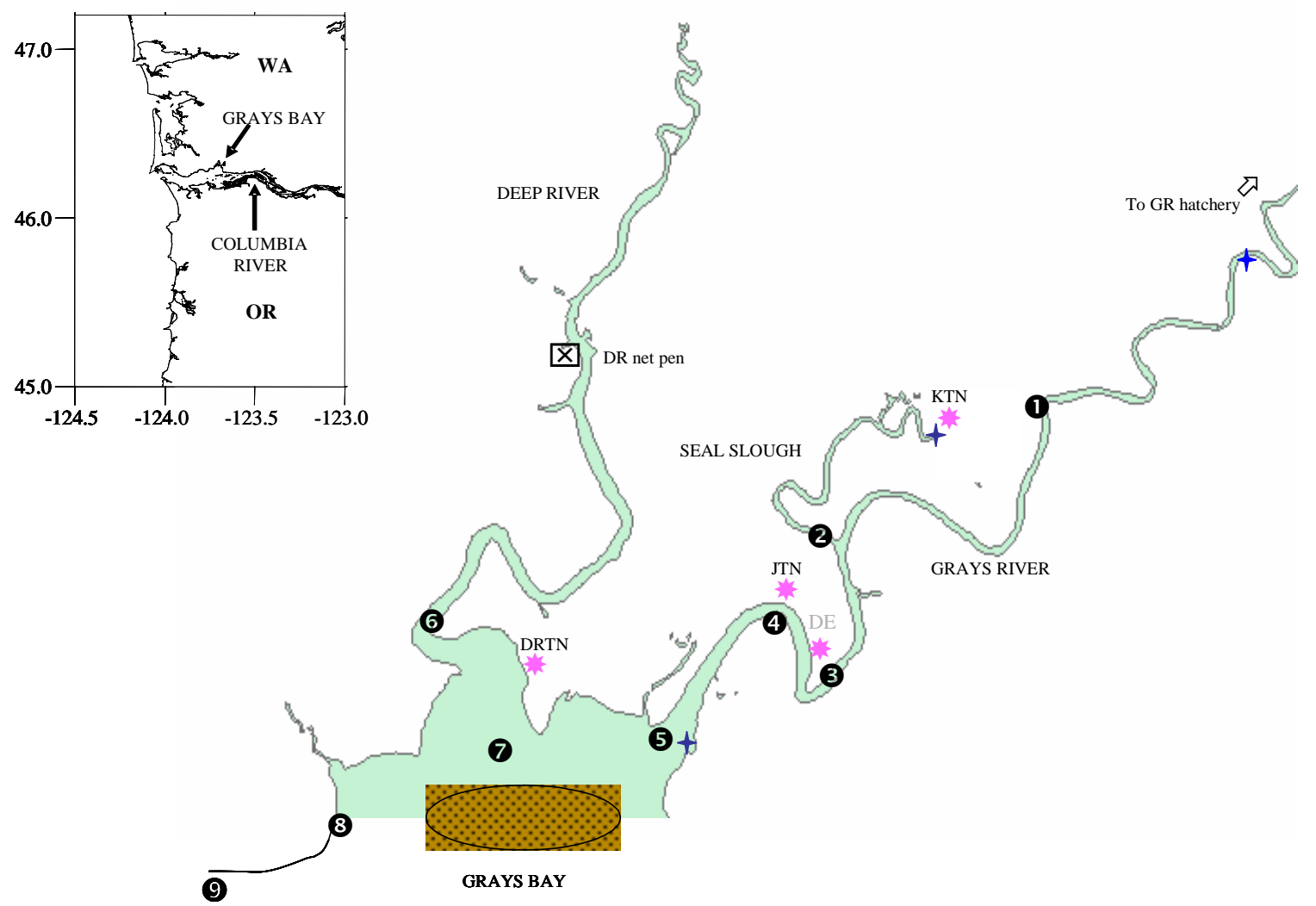

Figure 4. Survey area in lower Grays River and upper Grays Bay for marked chum salmon fry released during the life history experiment and for salmon diet analyses. For the marking study we sampled five sites in lower Grays River (1-5) and four sites in upper Grays Bay (7 - 9) with a beach seine. Two wetland channels in lower Grays River (KTN and JTN) and a single wetland channel between the confluence of Grays River and Deep River (DRTN) were sampled with a fyke trap net. We also collected Chinook, chum, and coho salmon for diet analysis at beach seining sites 1-5, at two restoring wetland channels at JTN, and at the forested wetland channel at DE.

\section{Wetland prey resources and salmon diets}

In addition to studies of juvenile salmon diet and prey availability in restoring and natural wetland habitats in the lower Grays River estuary, as a major component of M.S. thesis research (C. Eaton), we investigated potential prey resource partitioning among salmon species and life history types, and its effects on individual (modeled) fish growth. We also compared diet and growth results to the available prey produced within restoring and natural wetlands and the prey exported to the lower river.

Between March and July we collected for diet analysis up to five unmarked Chinook, chum, and coho salmon of several size classes from each the following sampling sites: two restoring emergent marshes (Johnson East; Johnson West) (JTN Figure 4)), one natural tidal forested site (Devils Elbow, DE Figure 4), and five mainstem 
beach seine sampling sites (sites $1-5$, Figure 4). Captured fish were euthanized using MS-222, and fork lengths and weights were recorded. Stomach contents were either immediately sampled by gastric lavage or, in the case of migrant fry $<55 \mathrm{~mm}$ FL long, preserved frozen. Water temperature was recorded every 10 minutes at each sampling site using temperature data loggers (Stowaway Tidbit ${ }^{\mathrm{TM}}$ ).

We analyzed diets in the laboratory with a dissecting microscope. Each stomach was assigned a fullness value (1-empty to 6-full), and the contents were blotted dry and weighed to the nearest $0.0001 \mathrm{~g}$. Stomach contents were sorted and identified to the highest taxonomic level possible. Each prey taxa-life history group was counted and weighed (blotted dry) individually. A digestion level rating was assigned to each stomach based upon the percentage of the total contents that was identifiable (1-nothing identifiable to 6-everything identifiable).

As an indicator of feeding intensity, the instantaneous ration (IR) was calculated as the total stomach content weight divided by the weight of the fish. We estimated percent numerical and gravimetric prey compositions and calculated the percent total Index of Relative Importance (Total IRI) as: \% frequency of occurrence (\% numerical composition + \% gravimetric composition).

In conjunction with our (trap net) sampling for juvenile salmon diet, we sampled prey availability using three techniques: (1) insect fall out traps (FOT); (2) benthic cores; and, (3) neuston traps. Five insect fallout traps were set haphazardly along each study channel. The fallout trap consisted of a 58.4-cm x 40.6-cm x 15.2-cm clear plastic tub (approximately 26.5L total capacity) surrounded by four PVC poles (approximately $2.5 \mathrm{~cm}$ diameter, $1.5 \mathrm{~m}$ tall) to keep the tub in place during the rising and falling tide. Each tub was filled approximately one-quarter full with soapy water and left to sample for two tidal cycles (approximately 48 hours). Each tub sample was sieved through a 106- $\mu \mathrm{m}$ sieve and preserved in 70\% isopropyl alcohol. In the laboratory, samples were examined under a dissecting microscope, and taxa were identified and counted to the highest taxonomic level possible. Particular attention was given to the identification of taxa found in the corresponding salmonid diets. Data are presented as number $\mathrm{m}^{-2}$.

Five macrobenthic cores were collected coincident with each trapnet sampling period when juvenile salmon stomachs were retained for dietary analysis. One core was collected adjacent to each insect fallout trap in the channel bottom at low tide. Cores were collected by inserting a coring device (5.2-cm inner diameter) into the channel bottom to a depth of $10 \mathrm{~cm}$. Samples were sieved through a 500- $\mu \mathrm{m}$ sieve and fixed in a $10 \%$ buffered formalin solution stained with rose bengal.

In mid-May, we also conducted a pilot experiment to document the export of neustonic organisms (including drift) from the two Johnson restoring marsh channels and the Devils Bend forested channel. We compared densities from riverine input at the smolt trap and at seven sites along the lower mainstem channel during high and low tide. 


\section{Coho life history studies}

As the basis for M.S. graduate student thesis research conducted by B. Craig, we investigated the estuarine ecology and life history variation of juvenile coho salmon outmigrants in natural and restoring wetland habitats of the Grays River estuary. We compared juvenile coho life history types during three phases of migration by sampling in selected fresh-water tributaries (electrofishing gear), near the head of tide (smolt trap), and in the Grays River estuary (marsh channel trap net; main-stem river channel beach seine). Coho life history types were differentiated based on size, relative age, and migration timing/residence time at each of the three migration phases.

We measured fork length and weight of all or representative subsamples $\left(\mathrm{n}_{\max }=\right.$ 10 per size interval) of juvenile coho collections, and collected scale samples for aging and further life history determination. Plastic acetate impressions of the scales were visually inspected to determine fish age (by presence of annuli). Scale impressions were digitized to count circuli and measure scale radius and circuli spacing using a computerized image analysis system. We grouped circuli patterns to compare growth rates between periods and among individual fish and used multivariate (e.g., discriminate analysis) statistical methods to classify life history types based on these scale patterns.

\section{Results and Discussion}

\section{Historical Hydrographic Surveys}

A complete digital elevation model (DEM) of the historical bathymetry for the Columbia River estuary is now complete and available (Figure 1). The digital dataset extends from the mouth of the Columbia River to Rkm 218, which is in the vicinity of Rooster Rock State Park. Our next step is to edit the H-sheet dataset for classification compatibility and spatial consistency with the historical T-sheets to create a seamless historical landscape of the estuary for spatial analyses. We will use this integrated dataset to characterize the historical land cover classes and landscape features relevant to juvenile salmon habitats, and compare these results with contemporary data.

\section{Chinook Salmon Residency and Growth}

Barium was present in juvenile Chinook salmon otoliths from all tidal fresh wetland sites sampled in the lower Columbia River estuary, including the uppermost site at Lord Island (Rkm 101). These results imply that the Ba signal is incorporated into salmon otoliths anywhere from Rkm 101 to the mouth and most likely, further upriver. Published data from other rivers suggest that Ba concentrations in water are often maximum between the head of tide and the area of salinity intrusion (Coffey et al. 1997, Colbert and McManus 2003).

The presence of a Ba signal on very small juvenile Chinook leads us to believe that $\mathrm{Ba}$ is incorporated in the lower tidal freshwater portion of the estuary. The otolith $\mathrm{Ba}$ 
signal was present in newly emerged fry $(37-44 \mathrm{~mm})$ captured at Lord, Wallace, Welch, and Russian islands, indicating recent entry into a Ba-rich environment (Figure 5). Because yolk absorption typically occurs at fish sizes between $32 \mathrm{~mm}$ and $36 \mathrm{~mm}$, relatively few daily growth increments were incorporated between the point of yolk absorption and the time of increased Ba concentration near the outer otolith edge. Among fry migrants, we estimated that only a few days to a week could have transpired between the time of emergence from the gravel in tributary streams and the time of capture at our estuary sites. Thus, we interpret the otolith Ba signal among newly emerged fry as an indicator of migration from tributary habitats and subsequent entry into the tidal fresh estuary just prior to capture.

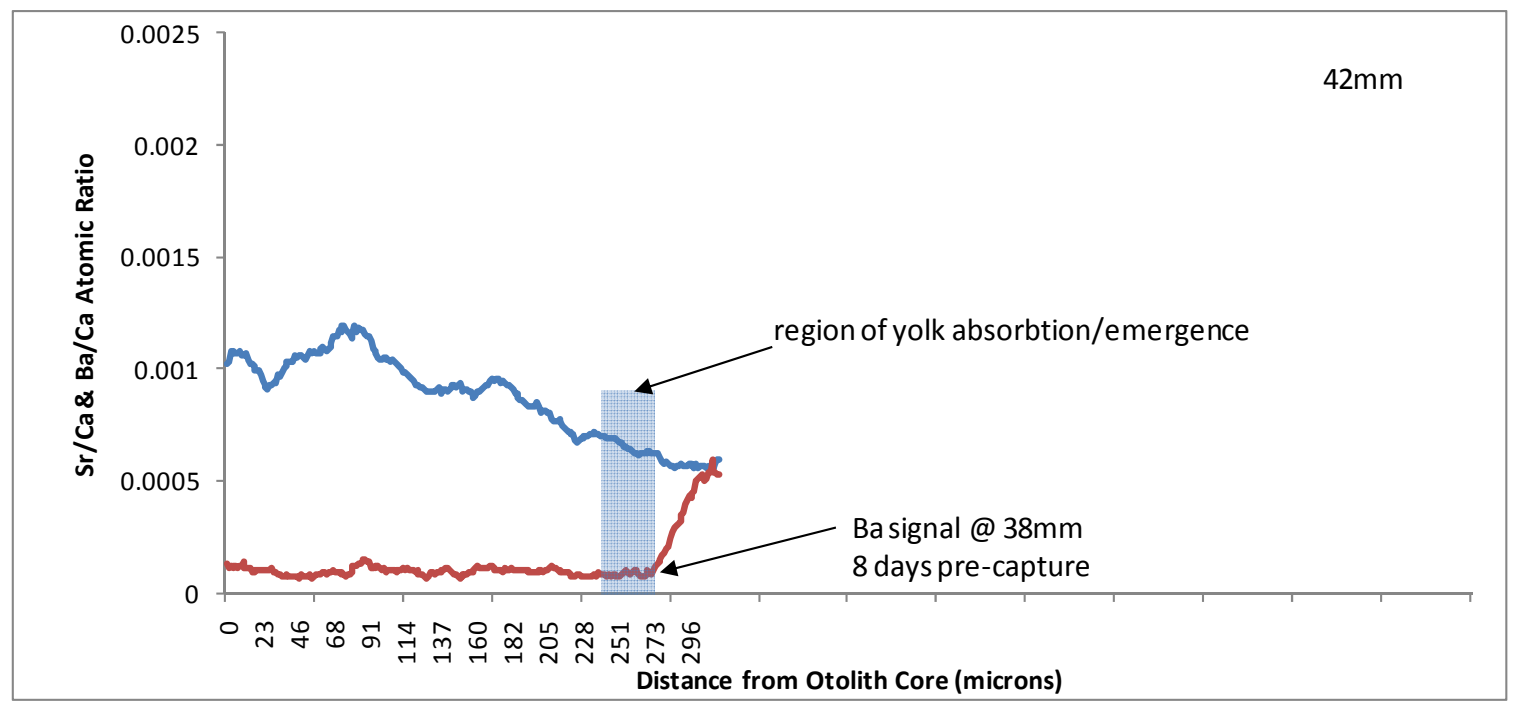

Figure 5. Sr (blue) and Ba (red) profiles from the otolith of a 42mm juvenile Chinook salmon captured at Lord Island (Rkm 101). The Ba signal deposited near the otolith edge implies recent arrival in the tidal fresh portion of the estuary

The Ba marker on salmon otoliths indicates considerable life history variation among the individuals that occupied estuarine wetlands. Among all samples, estimated individual residence times in Ba-rich water ranged from 0 to $82 \mathrm{~d}(\bar{x}=33 \mathrm{~d}$ ) prior to capture. Fifteen percent of the otolith samples had no Ba signal, suggesting these individuals had recently arrived ( $<6 \mathrm{~d}$ based on our earliest detection) to the region where Ba could be incorporated into the otolith.

For each individual with a Ba signal on its otolith, we back-calculated size of entry into Ba-rich water (Figure 6). Estimated size at the beginning of the Ba signal for all individuals ranged from 33 to $89 \mathrm{~mm}$, and averaged $45 \mathrm{~mm}$. By comparison, entry sizes for 5 marked hatchery fish collected throughout our survey area (Figure 2) averaged $82 \mathrm{~mm}$ at capture. The Ba signal for these individuals was typically 500 microns from the primordium, representing a back-calculated size of approximately $73 \mathrm{~mm}$ at entry into Barich water. Because most hatchery fish are released above the estuary at relatively large 
sizes, this result is consistent with the hypothesis that otolith $\mathrm{Ba}$ is incorporated following tidewater entry.

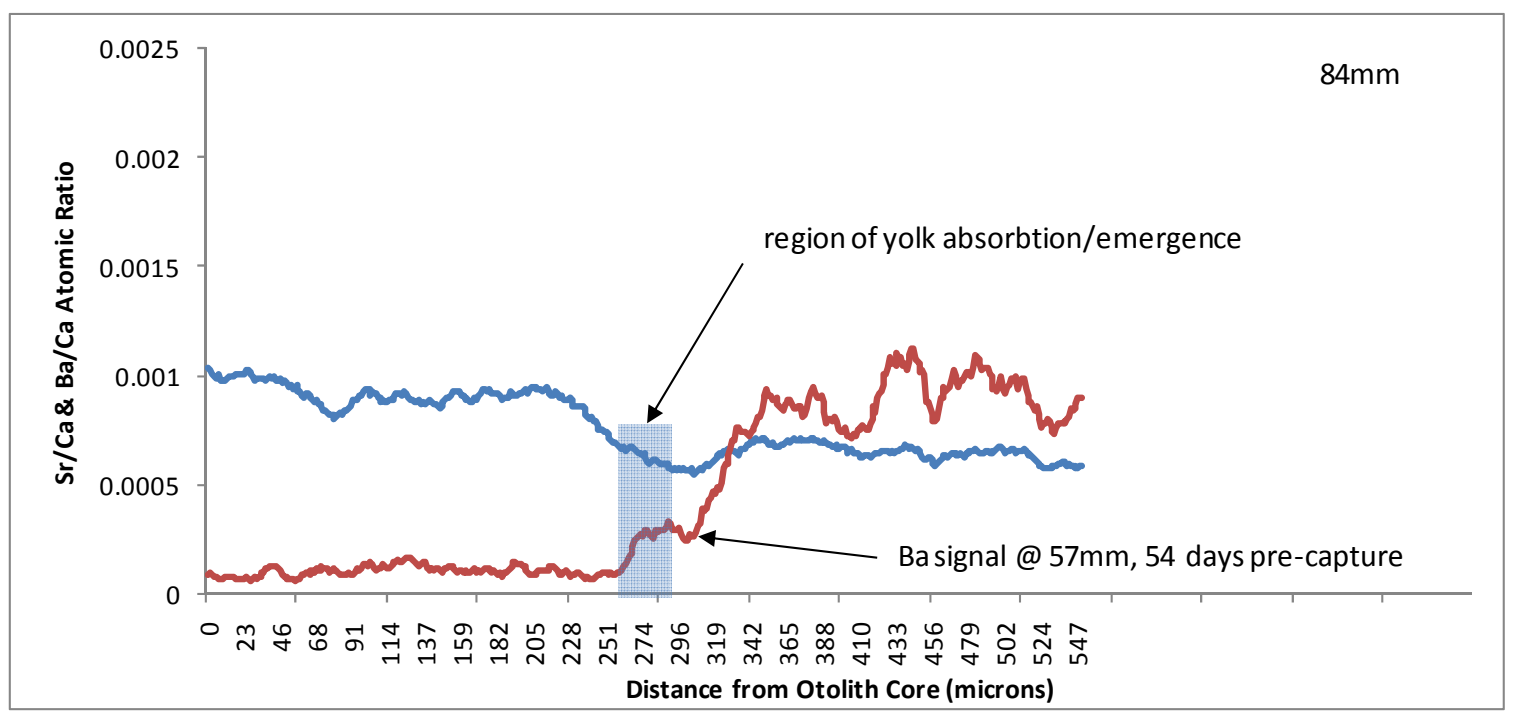

Figure 6. Sr (blue) and Ba (red) profiles from the otolith of an $84 \mathrm{~mm}$ juvenile Chinook salmon captured at Russian Island. Estimated residence time in Ba-rich water was nearly two months.

Our preliminary results suggest that elevated otolith Ba concentrations generally dissipate soon after salmon enter the saline portion of the estuary, suggesting Ba could be a distinct indicator for the lower boundary of the tidal-fresh estuary (Figure 7). For example, one individual captured at Point Adams Beach in the lower estuary (Figure 2) first encountered Ba-rich waters at an estimated size of $72 \mathrm{~mm}$ FL. At approximately 82 $\mathrm{mm} \mathrm{FL}$, otolith $\mathrm{Sr}$ concentrations in the same individual began increasing-indicating salt-water entry - while Ba concentrations rapidly declined. If $\mathrm{Ba}$ is a valid indicator of residency in the tidal-fresh environment, then this individual had remained in the tidal fresh zone for approximately 20 days before spending another 94 days in the saline portion of the estuary. 


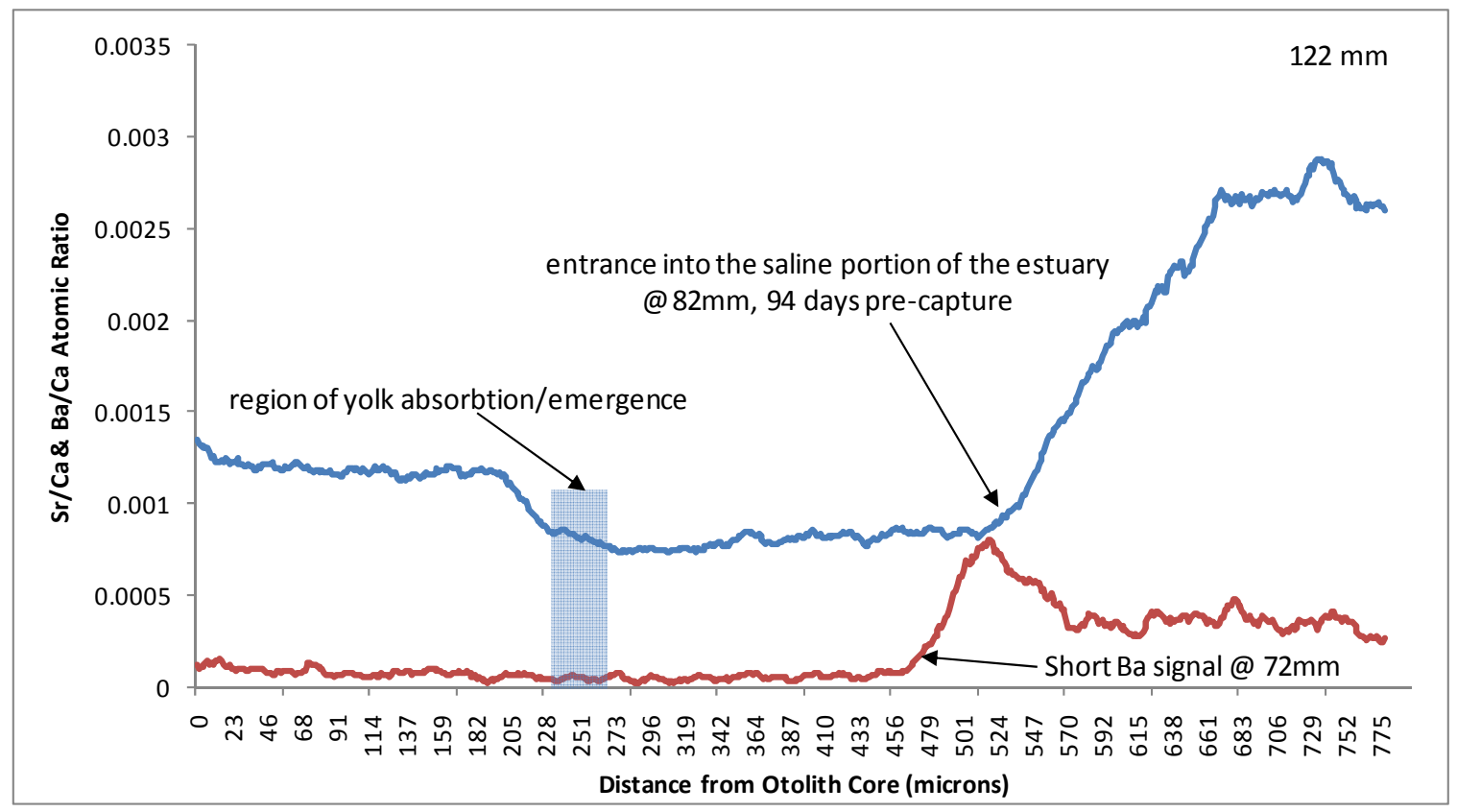

Figure 7. Sr (blue) and Ba (red) profiles from the otolith of a $122 \mathrm{~mm}$ juvenile Chinook salmon captured at Point Adams Beach. Notice the short rise in Ba preceding the $\mathrm{Sr}$ inflection, which we interpret as relatively rapid movement through the tidal fresh zone before this individual resided for three months in the lower saline portion of the estuary.

Based on our analysis of daily growth increments for 30-day intervals, we estimated individual growth rates of Chinook salmon collected in wetland habitats ranged from a minimum of $0.38 \mathrm{~mm} \mathrm{~d}^{-1}$ in April to a maximum of $0.73 \mathrm{~mm} \mathrm{~d}^{-1}$ in June. Monthly average growth rates for salmon were similar among the wetland sites, ranging from approximately 0.4 to $0.6 \mathrm{~mm} \mathrm{~d}^{-1}$ (Table 1 ). Despite relatively low sample sizes for the otolith increment analyses, mean monthly growth rates exhibited a consistent positive trend at all sites coincident with increasing estuary water temperatures from April through June (Roegner et al. 2009). Mean growth estimates for individuals sampled at wetland habitats were similar to previous estimates for fish collected at lower-estuary beach-seining sites, which averaged from 0.45 to $0.86 \mathrm{~mm} \mathrm{~d}^{-1}$ in 2002 and 2003 (Roegner et al. 2009).

Table 1 Average mean increment width (MIW) and growth rate in $\mathrm{mm} \mathrm{d}^{-1}$ over 30 days pre-capture. Monthly samples were collected mid month. Therefore April samples estimated growth from mid March through mid April and so on for May and June.

\begin{tabular}{|c|c|c|c|c|c|c|c|c|c|}
\hline \multicolumn{3}{|c|}{ Russian Is } & \multicolumn{3}{|c|}{ Wallace Is } & \multicolumn{2}{|c|}{ Lord Is } & \multirow[b]{2}{*}{$\mathrm{mm} \mathrm{d}^{-1}$} & \multirow[b]{2}{*}{$\mathrm{n}$} \\
\hline Month & MIW (microns) & $\mathrm{mm} \mathrm{d}^{-1}$ & $\mathrm{n}$ & MIW (microns) & $\mathrm{mm} \mathrm{d}^{-1}$ & $\mathrm{n}$ & MIW (microns) & & \\
\hline April & 2.04 & 0.41 & 3 & 2.2 & 0.43 & 4 & 2.3 & 0.44 & 3 \\
\hline May & 2.79 & 0.51 & 4 & 2.66 & 0.5 & 2 & 2.96 & 0.54 & 3 \\
\hline June & 3.22 & 0.58 & 4 & 3.53 & 0.62 & 4 & 3.58 & 0.63 & 5 \\
\hline
\end{tabular}


Although the otolith chemistry results appear promising, additional analyses will be needed to validate whether $\mathrm{Ba}$ is a reliable indicator of the juvenile life history of Columbia River salmon. Our interpretations assume that elevated Ba does not occur in fresh water tributaries and will not produce an otolith signal at main-stem sites above tidal influence. This assumption still must be verified. Moreover, unlike Sr, which is closely correlated with seawater, Ba has no such correlation and likely varies with flow, location, and season (Coffey et al. 1997, Colbert and McManus 2003). Validation of Ba as a life-history indicator will require collecting juvenile salmon from a greater range of tidal fresh environments to determine the locations (by season and flow regime) where elevated otolith Ba concentrations first appear in otoliths. Of particular importance are mainstem habitats above Rkm 101 (to Bonneville Dam) and the tidal fresh reaches of selected estuary tributaries.

\section{Salmon Life History and Prey Resources in a Tributary Estuary}

\section{Chum salmon residency}

During repeated beach seine surveys on consecutive days following the experimental release of hatchery chum salmon in Grays River, we recaptured no marked individuals in Grays River or upper Grays Bay. We evaluated several alternative explanations to account for the absence of marked hatchery fry. First, we tested whether juveniles may have remained in Grays River above our lower estuary sampling sites by beach seining in tidewater reaches nearer the release site. Finding no marked chum salmon upriver, we concluded that it is unlikely individuals delayed their migration to the lower estuary.

We also evaluated whether poor mark retention could account for the absence of marked individuals during our post-release surveys. Mark retention estimates from samples held at Grays River Hatchery were 64\%, 60\%, and 24\% for the orange, yellow, and red groups, respectively. Although these estimates were surprisingly low, it seems likely we would have recaptured at least a few individuals, if a significant proportion of the nearly 150 thousand fish released was present in the Grays River estuary during the recapture period. As further evidence of this conclusion, on April 1, when the size range of salmon among the survey sites was greatest, unmarked chum salmon averaged $40 \mathrm{~mm}$ at the lower river beach-seine sites $(r=37-44 \mathrm{~mm}$, $\mathrm{sd}=2)$ and $41 \mathrm{~mm}(\mathrm{r}=36-49 \mathrm{~mm}$, sd = 3) at the Grays Bay survey site \#7 (Figure 4). Despite possible overlap, particularly with some individuals from the smallest (red) experimental group ( $\bar{x}=43.0 \mathrm{~mm}$, sd 2.4), the majority of fish released from Grays River Hatchery were larger than the individuals we collected during the recapture surveys. It is likely that the chum salmon we sampled in lower Grays River were the progeny of adults that had spawned naturally in the Grays River watershed.

The most likely explanation for our negative results is that chum salmon exited the system within hours of their release and thereby eluded recapture. The approximate 
in-river distance from the release site to the mouth of Grays River was $19.25 \mathrm{~km}$. Site observations suggest that flows near the release site were approximately $1 \mathrm{~ms}^{-1}$. At that rate a passively drifting particle could have traveled the distance to the river mouth in as little as 5 hours, about the duration of the ebbing tide (Figure 8). If we account for reversing tidal flows, assuming average velocities between 0.2 and $1 \mathrm{~ms}^{-1}$, we estimate that at least some individuals could have been present in the river and upper Grays Bay during the first day or two after release. However, it seems likely that individuals actively migrated downstream. Even with moderate swimming speeds, we estimate that downstream migrants could have augmented tidal velocities and readily covered the distance to the river mouth beyond our recapture sites on day 1 . Because rapid exit seems a strong possibility, and because chum salmon therefore may not offer a useful test of size-dependent rearing behavior by more estuarine-resident salmonid species (i.e., Chinook and coho salmon), we have no plans to repeat the chum salmon release experiment during the Phase II study.

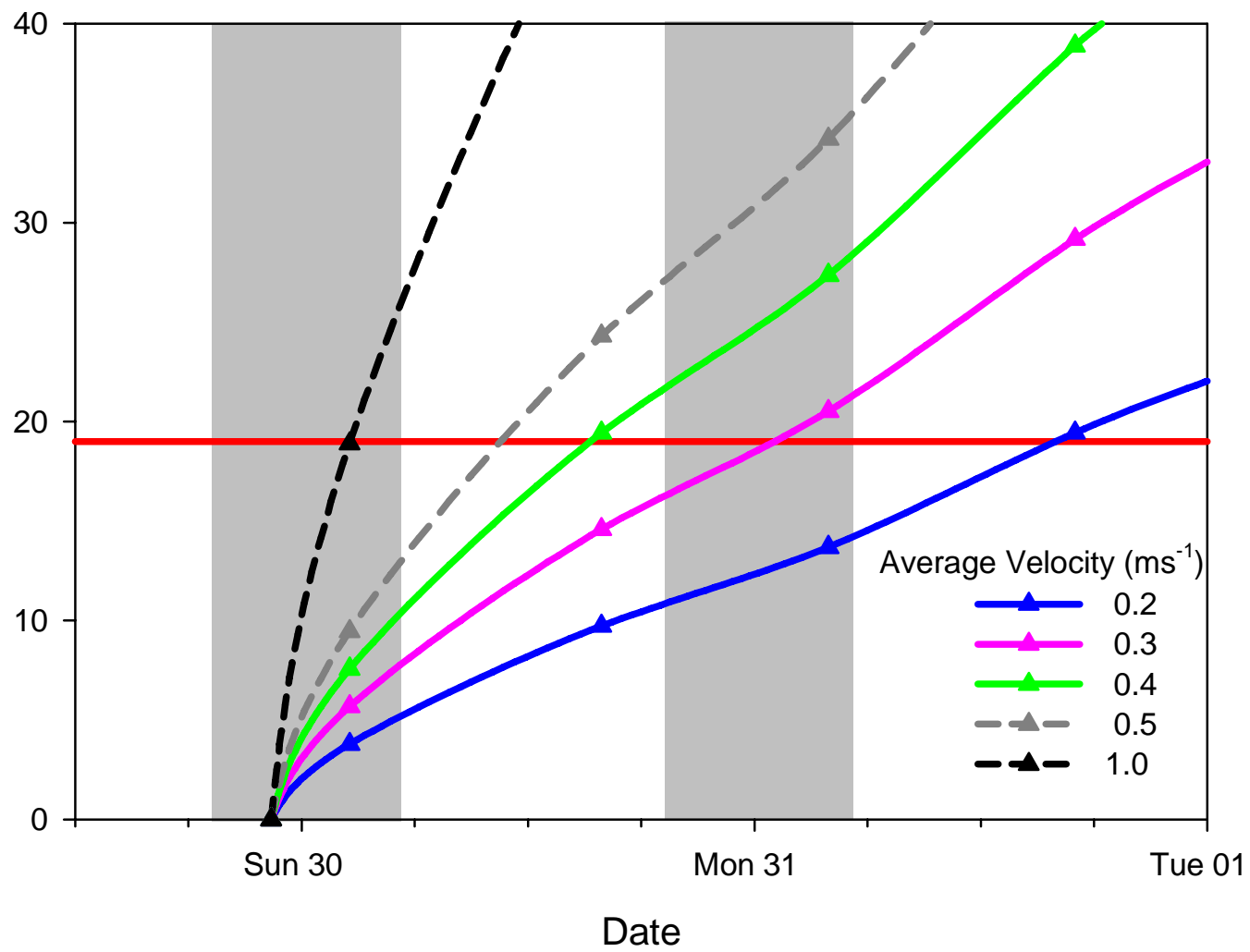

Figure 8. Cumulative transport under ebb flow conditions for various flow velocities. Grey bars denote periods of darkness, red line is mouth of Grays River. 


\section{Coho salmon life history}

The variety and complexity of the estuarine wetland habitats in lower Grays River, including several restoring wetlands, provides rearing opportunities for a diversity of coho salmon life histories. From our initial analyses we distinguished at least four life history types migrating from the Grays River watershed into the estuarine study area: (1) fry migrants that entered the estuary from late February through April and occurred within the estuarine wetlands through mid-June; (2) parr and pre-smolt migrants from late February through early May that appeared less frequently in the wetland channels as smolts from April through June; (3) a pulse of larger smolts that entered in late May to early June; and, (4) a late group of parr and pre-smolt migrants after June that likely resided in the estuary until at least August. Subyearling coho appeared to select wetland channel rearing areas, wheras larger yearling smolts were found more frequently in the main-stem river. In addition, habitat selection by subyearling coho salmon appeared size dependent, with smaller fish selecting smaller channels.

Based on scale analysis, earlier migrating coho appeared to have better growth than fish captured in wetlands later in the migration period. All early subyearling migrants, both those captured in the wetlands and at the estuary entrance, grew more rapidly and were a larger size-at-age compared with yearling smolts that migrated from the watershed. However, subyearling coho captured in the estuary wetlands later in the migration period had relatively reduced growth rates compared with early-caught subyearlings.

Additional analyses of juvenile coho life history are planned in 2009 including: (1) relative growth patterns from fry and early migrating parr, pre-smolts and smolts; and, (2) migration rates and estuarine residency of different life history types, based on markrecapture and other experimental treatments.

\section{Wetland prey resources and salmon diets}

A total of 208 juvenile salmon were retained for diet analyses from 2008 sampling: 63 Chinook; 73 coho, and 72 chum. Results of the diet composition indicated that juvenile coho salmon had more diverse diets and greater instantaneous ration than juvenile Chinook or chum salmon. Mean number of prey taxa ranged between 2 and 6 for chum salmon, 5 and 8 for Chinook salmon, and 4 and 14 for coho salmon. Emerging and larval chironomid (Diptera) flies tended to dominate the gravimetric (i.e., based on weight) diet composition of chum and Chinook salmon, although other insects (Cantharidae, Ephemeroptera, Trichoptera) also contributed to their diets. Benthic crustaceans (especially the gammarid amphipod Anisogammarus) and polychaete annelids dominated the gravimetric contribution to juvenile coho salmon diet.

Feeding differences among habitats were most evident for juvenile coho, the only species consistently captured in the forested wetland. Diet composition consisted of a wide array of insects (all life history stages of Diptera; Cantharidae; Trichoptera) in the 
forested wetland but was dominated by Anisogammarus and oligochaetes in the restoring marshes. In addition to a more diverse diet, juvenile coho usually had higher instantaneous rations than the other salmonid species. Chum and Chinook salmon IR values consistently were $<1 \%$ ( $g_{\text {diet }} / g_{\text {body weight }}$ ), whereas the estimated IR for juvenile coho salmon frequently exceeded $1 \%$ and, in one case, was $>2.5 \%$. Within the mainstem river, diet richness consistently decreased from adjacent wetlands downstream toward Grays Bay, suggesting that the wetland channels were the source of exported insects.

Fall-out trap (FOT) insects were consistently more diverse in the forested tidal wetland than in the restoring emergent wetlands, increasing from average species richness of 3 (Johnson site) to 7 (forested site) in February to 13 and 19 in June, respectively. Samples from both restoring and natural tidal forested wetlands were broadly similar, both dominated by dipteran flies and diverse collembolan (springtails) taxa; however, dipterans were much more prominent in the Johnson restoring site from February through May than at the tidal forested wetland site (where collembolans were more common during more months). FOT densities also tended to be higher in the forested than in the Johnson wetland until June, when mean FOT insect densities in the restoring wetland were more than $5 \mathrm{X}$ those estimated in the forested wetland. However, densities of chironomid flies, the prominent juvenile salmon prey taxa, were generally higher in the restoring wetland than in the forested wetland (except in April).

Preliminary analysis of benthic macroinvertebrate samples from 2008 indicated that nematodes and oligochaetes dominated both restoring and forested tidal wetland sites, but insects (collembolans, dipteran larvae) and crustaceans (isopods, gammarid amphipods such as Anisogammarus spp.) added additional diversity (constituting more than $25 \%$ of the benthic invertebrate abundance) at the restoring site. 


\section{References}

Anderson, G. A. 2006. Variations in estuarine life history diversity of juvenile Chinook salmon based on stable isotope analysis of food web linkages. M.S. Thesis. University of Washington, Seattle.

Bottom, D. L., G. Anderson, A. Baptista, J. Burke, M. Burla, M. Bhuthimethee, L. Campbell, E. Casillas, S. Hinton, K. Jacobson, D. Jay, R. McNatt, P. Moran, G. C. Roegner, C. A. Simenstad, V. Stamatiou, D. Teel, and J. E. Zamon. 2008. Salmon Life Histories, Habitat, and Food Webs in the Columbia River Estuary: An Overview of Research Results, 2002-2006. Report of Research by Northwest Fisheries Science Center, National Marine Fisheries Service, Seattle, WA.

Bottom, D. L., C. A. Simenstad, A. M. Baptista, D. A. Jay, J. Burke, K. K. Jones, E. Casillas, and M. H. Schiewe. 2005. Salmon at River's End: The Role of the Estuary in the Decline and Recovery of Columbia River Salmon. NOAA Technical Memorandum NMFS-NWFSC-68. 246pp.

Brenkman, S. J., S. C. Corbett, and E.C. Volk. 2007. Use of otolith chemistry and radiotelemetry to determine age-specific migratory patterns of anadromous bull trout in the Hoh River, Washington. Transactions of the American Fisheries Society 136: 1-11.

Campana, S.E. 1990. How reliable are growth back-calculations based on otoliths? Canadian Journal of Fisheries and Aquatic Sciences 47:2219-2227.

Coffey, M., F. Dehairs, O.Collette, G. Luther, T. Church, and T. Jickells. 1997. The behavior of dissolved barium in estuaries. Estuarine, Coastal and Shelf Science 45:113-121.

Colbert, D., and J. McManus. 2003. Importance of seasonal variability and coastal processes on estuarine manganese and barium cycling in a Pacific Northwest estuary. Continental Shelf Research 25:1395-1414.

ESRI [Environmental Systems Research Institute, Inc.]. 2009. ArcGIS 9.3 software. ESRI, 380 New York Street, Redlands, CA 92373-8100, USA. URL: http://www.esri.com

Koski, K V. 2009. The fate of coho salmon nomads: the story of an estuarine-rearing strategy promoting resilience. Ecology and Society 14(1): 4. [online] URL: http://www.ecologyandsociety.org/vol14/iss1/art4/

Lott, M. A. 2004. Habitat-specific feeding ecology of ocean-type juvenile Chinook salmon in the lower Columbia River estuary. M.S. Thesis, University of Washington, Seattle. 
McGarigal, K., S. A. Cushman, M. C. Neel, and E. Ene. 2002. FRAGSTATS: Spatial Pattern Analysis Program for Categorical Maps. Computer software program produced by the authors at the University of Massachusetts, Amherst. Available at the following web site: www.umass.edu/landeco/research/fragstats/fragstats.html

Roegner, G.C., A. Baptista, D. L. Bottom, J. Burke, L. Campbell, C. Elliot, S. Hinton, D. Jay, M.A. Lott, T. Lundrigan, R. McNatt, P. Moran, C. A. Simenstad, D. Teel, E. Volk, J. Zamon, and E. Casillas. 2009. Estuarine habitat and juvenile salmon-current and historical linkages in the lower Columbia River and estuary, 2002-04. Fish Ecology Division, Northwest Fisheries Science Center, Seattle, WA.

Thomas, D. W. 1983. Changes in the Columbia River estuary habitat types over the past century. Columbia River Estuary Data Development Program. Astoria, OR.

Volk, E.C., A. Blakley, S. L. Schroder, and S.M. Kuehner. 2000. Otolith chemistry reflects migratory characteristics of Pacific salmonids: Using otolith core chemistry to distinguish maternal associations with sea and fresh waters. Fisheries Research 46:251-266

Zimmerman, C. E., and G. H. Reeves. 2002. Identification of steelhead and resident rainbow trout progeny in the Deschutes River, Oregon, revealed with otolith microchemistry. Transactions of the American Fisheries Society 131:986-993. 